\title{
OS CINCO MÉTODOS CARACTERÍSTICOS DE UM PROCESSO DE APRENDIZAGEM SOB A ÓTICA DO FILÓSOFO E PEDAGOGO ISAAC WATTS NO SÉCULO XVIII
}

\author{
Ingrid Derossi" \\ Ivoni Freitas-Reis ${ }^{* *}$
}

\begin{abstract}
Resumo: O objetivo deste trabalho é abordar os métodos para o aperfeiçoamento da mente, desenvolvidos por Isaac Watts em 1741. Por tratar de instruções para o aperfeiçoamento da mente e pretender ser um minucioso guia para tutores e estudantes, essa obra foi bastante utilizada por cientistas comprometidos com o ensinar, tais como os ingleses Michael Faraday e Jane Marcet. Entretanto, apesar de encontrarmos reedições bastante atuais ela ainda é muito pouco discutida.
\end{abstract}

Palavras-Chave: Isaac Watts; Ensino; Aperfeiçoamento da mente; Aprendizagem; Século XVIII

Resumen: El objetivo de este trabajo es abordar los métodos para el perfeccionamiento de la mente, desarrollados por Isaac Watts en 1741. Por tratar de instrucciones para el perfeccionamiento de la mente y pretender ser una minuciosa guía para tutores y estudiantes, esta obra fue bastante utilizada por científicos comprometidos con la enseñanza, tales como los ingleses Michael Faraday y Jane Marcet. Sin embargo, a pesar de encontrar reediciones bastante actuales, todavía es muy poco discutida.

Palabras claves: Isaac Watts; Educación; Mejoramiento de la mente; Aprendizaje; Siglo XVIII

\section{Introdução}

Isaac Watts (1674-1748) nasceu em Southampton em dezessete de julho de 1674, em uma família envolvida com o ensino, seu pai era mestre em uma escola semelhante a um internato de excelente reputação. Watts apresentou uma precoce atração pelos livros, aos quatro anos de idade começou a aprender Latim e aperfeiçoou através das aulas dadas pelo reverendo John Pi-

\footnotetext{
* Doutoranda em Educação Química na Universidade Federal de Juiz de Fora, ingriderossi@gmail.com.

" Professora Adjunta IV do Departamento de Química da Universidade Federal de Juiz de Fora, ivonireis@gmail.com.
}

nhorne (1652-1714) $)^{3}$, e depois, foi-lhe ensinado o Grego e Hebraico (GIBBONS, 1780)

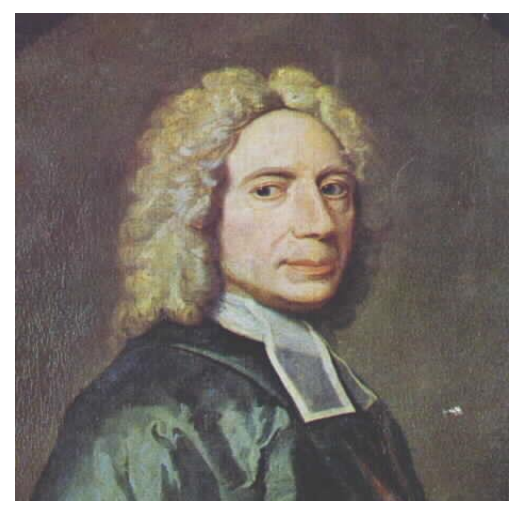

Figura 1: Isaac Watts

(Fonte: http://www.poetryfoundation.org/bio/isaacwatts)

A sua dedicação e eficiência, fizeram com que algumas pessoas da alta sociedade de Southampton se interessassem pelo jo-

\footnotetext{
${ }^{3}$ Um mestre independente ou autônomo figura muito presente na Inglaterra dos séculos XVI a XVIII.
}

DEROSSI, Ingrid; FREITAS-REIS, Ivoni. Os cinco métodos característicos de um processo de aprendizagem sob a ótica do filósofo e pedagogo Isaac Watts no século XVIII. Revista Sul-Americana de Filosofia e Educação. Número 28: maio-out./2017, p. 141-155. 
vem aprendiz e lhe ofertassem uma quantia suficiente para mantê-lo em uma universidade. Em 1690, Isaac foi para uma Academia, que de acordo com o prefácio de seu livro, era muito bem estruturada pelo reverendo Thomas Rowe. Três anos depois, entrou para a congregação ainda sob os cuidados de Rowe. Ocupou seus horários livres com literaturas poéticas e depois de deixar a academia, aos vinte anos, dedicou dois anos de sua vida à leitura, à meditação e à oração, preparando-se para o cargo de ministro da congregação. (WATTS, 1743)

Ao final dessa época, ele foi convidado por Sir John Hartopp (1637-1722) a morar com a sua família em Stoke Newington, perto de Londres, atuando como tutor de seu filho John IV (1680-1762), onde permaneceu até 1698, ano em que Watts fez seu primeiro sermão tornando-se assistente do Dr. Isaac Chauncy (1632-1701), ministro da congregação em Mark Lane. Após a morte do reverendo Chauncy, em 1701, Watts tornou-se seu substituto. (GIBBONS, 1780)

No século XVIII, Isaac Watts destacou-se por sua colaboração na criação dos hinos de igreja, sermões, bem como livros educacionais para crianças e trabalhos que envolveram a gramática, a lógica, a astronomia, a pedagogia, a ética e áreas afins. Neste trabalho abordaremos a obra The Im- provement of the Mind, que foi publicada pela primeira vez em 1741 como um suplemento a um trabalho anterior sobre lógica. No prefácio da obra, o autor justifica a produção:

Na última página do tratado de lógica, no qual eu publiquei há muitos anos atrás, é observado que há muitas outras coisas que podem ajudar o cultivo da mente e o seu aperfeiçoamento em conhecimento, do qual não é usualmente representado entre os princípios ou preceitos dessa arte ou ciência. Há assuntos que compõem esse livro, há sentimentos e regras, muito dos quais eu os tive em vista e agora me arrisco a tornar público. (WATTS, 1743, p. V)

Ainda no prefácio, Watts descreveu que o seu "tratado" é composto de observações, resultantes de seus próprios estudos, mas também de trabalhos de outros autores que também focavam na melhor maneira de aprender algo, ou ainda, tratavam de fatos da vida e instruções para o aperfeiçoamento da mente com conhecimento útil, além de ser um guia para estudantes que buscam maneiras sobre como estudar, obter conhecimentos e meios de aprendizagem. (WATTS, 1743) 


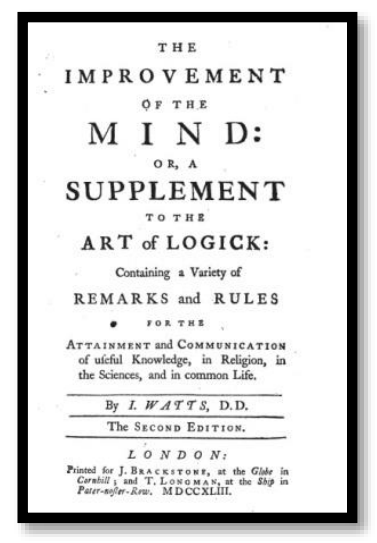

Figura 2: Primeira página do livro, 1743

(Fonte: WATTS, 1743)

Em sua primeira edição, o livro é dividido em duas partes, a primeira estabelece "observações e regras de como nós podemos alcançar o conhecimento útil através de estudos autodidatas", contendo a descrição dos métodos $^{4}$ para o aperfeiçoamento da mente e a segunda contém o "como nós podemos melhor nos comunicar com os outros" e em 1751 foi publicada pela primeira vez a obra na íntegra. (BALDINATO, PORTO, 2009)

O curioso sobre essa obra é que, embora seja possível encontrar (re)edições em praticamente todos os anos, desde a sua primeira publicação até 2016, existem poucos estudos disponíveis que tratem especificamente dela. Outro fator que demonstra o valor dado a esse trabalho é a sua utilização

\footnotetext{
${ }^{4} \mathrm{O}$ termo Método - que é utilizado por Watts e por alguns estudiosos do Século XIX, os quais também se apropriaram de seus escritos - é empregado para descrever os procedimentos para um "improvement" da mente, ou da razão, e será mantido por nós durante a maior parte do texto.
}

por parte de estudiosos, como Michael Faraday (1791-1867) e Jane Marcet (17691858).

A influência de Watts sobre Faraday pode ser observada pelo trecho abaixo de uma carta enviada pelo estudioso inglês para alguns de seus conhecidos com cópias da obra de Watts, a fim de divulgar a importância da obra, da qual pode ser possível verificar que Faraday utilizava pelo menos um dos métodos de Watts (meditação ou estudo) vejamos:

Um método verdadeiramente efi-
caz de melhorar a mente da pes-
soa que lhes escreve e de quem o
recebe. Uma forma de melhorar a
mente, pela recíproca troca de
conhecimentos. (p. 30)
Através da regra 9, uma vez ao
dia, especialmente nos primeiros
dias de sua vida de estudos,
chame você mesmo para um rela-
to dos avanços que tem feito em
qualquer parte do conhecimen-
to..." (HAMILTON, 2003. p.
130)

Empenhado em melhorar suas palestras, Faraday participou de aulas de oratória oferecidas por Benjamin Smart na Royal Institution (RI), nas tardes de quinta-feira no ano de 1818. Suas anotações continham aproximadamente cento e cinquenta páginas, eram detalhadas e intensas, demonstravam a sua determinação em ter um estudo 
preciso e em adquirir as ferramentas necessárias ao seu sucesso. O grande interesse demonstrado por Faraday em uma educação adequada para as crianças sofreu influência dos ensinamentos de John Locke (1632-1704) e Isaac Watts. (HAMILTON, 2003)

Em toda a obra de Watts pode-se perceber a presença das ideias de John Locke. Em vários pontos do The Improvement... o estudioso se remete a Locke ${ }^{5}$ deixando clara a sua apropriação e admiração sobre as ideias desse, como veremos a seguir. Desse modo, em várias ocasiões, iremos revisitar os conceitos de Locke, principalmente aqueles presentes na obra Ensaio acerca do entendimento humano (LOCKE, 1690), para este artigo iremos utilizar a vigésima sétima edição, de 1836, para melhor evidenciar o diálogo entre os referidos filósofos.

Para John Locke o conhecimento é adquirido através de processos denominados experiência sensivel que viria da interação com o meio externo e reflexão que viria do "interior do indivíduo" (MARTINS, MONTEIRO, 1978). Vejamos um trecho em que

\footnotetext{
${ }^{5}$ John Locke nasceu em vinte e nove de agosto de 1632, na cidade de Bristol e foi contra as ideias do inatismo, filosofia que afirmava que o homem já nascia com as ideias inatas, pensamentos de filósofos como Santo Agostinho (354-430), Santo Anselmo (1035-1109) e René Descartes (1596-1650).
}

Isaac Watts confessa que fora influenciado pelos estudos de John Locke:

Dos cinco eminentes métodos, por meio dos quais a mente está aperfeiçoando o conhecimento das coisas. [o primeiro seria] Observação: inclui tudo que $\mathrm{Mr}$. Locke quer dizer por sensação $e$ reflexão. (WATTS, 1743, p. 31)

Em outro segmento de sua obra é possível constatar a presença de aconselhamentos ou normas de como proceder para aprender ciências, que estão entremeados pelos preceitos de Locke, como a construção de esquemas, diagramas, bem como, recomenda que o aprendiz deva deixá-los em lugares que seriam vistos todos os dias, como em armários, corredores, como uma maneira de facilitar a memorização dos conceitos.

Dentre essas "regras de ouro", destacaremos os procedimentos que deverão ser adotados para um bom conferencista ${ }^{6}$, apresentados por Watts de acordo com a nossa livre tradução e interpretação.

\section{Os cinco métodos de Isaac Watts}

Em um primeiro momento o autor traz uma descrição geral dos seus cinco mé-

\footnotetext{
${ }^{6} \mathrm{O}$ autor utiliza-se da denominação conferencista, para se referir a professor, tutor, ministro de igreja, enfim, para todo aquele que se dispusesse a educar.
} 
todos, que são: Observação, Leitura, Instruções Verbais para as Palestras Públicas ou Privadas (Aulas), Conversação e Estudo ou Meditação. (WATTS, 1743)

O primeiro método abordado é a Observação. Segundo Watts, trata-se das "notas" que os indivíduos tomam de todas as ocorrências da vida, sejam elas sensíveis, ou intelectuais. As sensíveis seriam as observações captadas do meio externo ou, como Locke descreve, "todas as diferentes percepções produzidas em nós" (LOCKE, 1836, p. 52). As intelectuais são próprias do ser humano, construídas pela mente de cada um, como por exemplo, ideias relativas a pessoas ou coisas, que compõem o autoconhecimento, ou que são elaboradas para transmitir aos outros.

O segundo método a ser detalhado é a Leitura, que está relacionado com o conhecimento adquirido a partir dos trabalhos de outros autores. Através de publicações escritas o leitor passa a fazer parte dos sentimentos, observações, raciocínio e do conhecimento adquirido pelo estudioso, bem como das informações sobre outras épocas, no caso dos livros mais antigos. (WATTS, 1743, p. 32)

O terceiro método seria as Instruçóes Verbais para Palestras Públicas ou Privadas que são as instruções verbais dadas por um professor enquanto os aprendizes ouvem em silêncio. De acordo com Watts, através desse procedimento se aprende, por exemplo, matemática, através da apresentação de vários teoremas ou problemas, especulações ou práticas por demonstrações e operações, mostradas pelo professor com todos os instrumentos necessários para essas operações. (WATTS, 1743, p. 32)

O quarto método é a Conversação, no qual, através do mútuo discurso e investigação, compreendem-se os sentimentos uns dos outros, bem como busca-se expor os seus próprios sentimentos. Isto leva a entender que, se você não tem uma clara ideia do que é falado, deve esforçar-se para obter uma concepção mais expressiva através de investigação (WATTS, 1743, p.32), ou seja, o aluno ao estar diante dos experimentos apresentados, através da investigação, ele construiria um significado próprio de tudo o que estava vendo.

O quinto e último método, mas não menos importante, é a Meditação ou Estudo, que inclui todos os esforços mentais que fazemos para tornar tudo sobre os outros métodos acima apresentados, úteis para ampliarmos o verdadeiro conhecimento $e$ a sabedoria. É pela meditação, que são criadas as redes de conexões em relação aos fatos que passam através dos pensamentos dos apren- 
dizes nas ocorrências da vida, nas experiências e nas próprias observações.

\section{Observação}

Esse método segundo Watts, seria fornecido ao ser humano na infância, com uma rica variedade de ideias e proposições, palavras e frases. Ele é responsável por saberes sensoriais, como por exemplo, "que o fogo queima, que o sol é que fornece a luz, que o cavalo come relva..." (p.30) Todas essas coisas, que são percebidas pelos sentidos ou pela consciência ou mesmo que se sabe de uma maneira direta, através de qualquer exercício de reflexão ou raciocínio, pode ser chamado de observação. (WATTS, 1743)

Semelhante descrição é possível de ser encontrada na obra de Locke na qual o filósofo aborda "os passos pelos quais a mente alcança várias verdades", vejamos: "Os sentidos inicialmente tratam com ideias particulares, preenchendo o gabinete ainda vazio, $e$ a mente se familiariza gradativamente com algumas delas, depositando-as na memória e designando-as por nomes". (LOCKE, 1836, p.13)

Quando essa observação relatasse qualquer coisa que imediatamente produzisse preocupação ou curiosidade, isso induziria ao que Watts chama de Experiência, o autor diz que para conhecer ou para experi- mentar, é necessário despertar um sentimento, "um apetite", uma paixão... E define experimento como:

Quando nós estamos pesquisando a natureza ou propriedades de qualquer existência por vários métodos de experimentação, ou quando nós aplicamos algum poder adicional, ou estabelecemos algumas causas para trabalhar, observar quais os efeitos que eles poderiam produzir, esse tipo de observação é chamado experimento. (WATTS, 1743, p.31)

De acordo com Watts, é através da observação, que a mente primeiramente é ocupada com ideias simples e depois com as mais complexas, e assim, estabelecer-se-ia a base e o fundamento de todo o conhecimento, e capacitaria as pessoas para usar qualquer um dos outros métodos propostos para melhorar a mente (WATTS, 1743, p. 34). Para um melhor entendimento, buscamos as definições de ideias simples e complexas de Locke: Ideias simples são aquelas que a mente não pode formular, nem destruir, são obtidas a partir do que vemos e do que sentimos, ou seja, "elas já existem", e as ideias complexas são formadas a partir da reunião de várias ideias simples. (LOCKE, 1836, p.62; p.96)

Assim, podemos compreender que para os filósofos aqui mencionados, primeiramente o indivíduo tem contato com co- 
nhecimentos "pré-existentes", sendo esses provenientes de ideias simples (estabelecidas pela mente), obtidas através das sensações $e$ que a partir de um processo interno, de agrupamento das ideias complexas, frutos de reflexão, resultam de vários processos de relações entre as ideias simples e os conhecimentos, são "reorganizadas" de maneira a fazer sentido para a mente, ou para a razão.

Watts atribui grande destaque para a observação. Segundo ele é a partir dela que origina-se todo o nosso conhecimento, mesmo que tais observações sejam apenas ideias ou proposições, elas propiciariam relações que iriam gerar os conhecimentos desenvolvidos pela pessoa. É por meio da observação que vemos e conhecemos as coisas como elas são, ou como elas parecem ser para nós. Através dela temos a impressão de que os próprios objetos estão dentro da nossa mente, dando-nos uma clara e forte concepção das coisas, enquanto que, o conhecimento derivado de aulas, leituras $e$ conversação $^{7}$, sem o uso de uma observação meticulosa, irão nos fornecer mais uma cópia das ideias de outros homens, isto é, uma imagem da imagem do que outros nos transmitiram e, portanto, mais uma réplica do original, não algo (re)construído pela mente. (WATTS, 1743, p. 35)
Vale ressaltar mais uma vantagem apresentada por Watts para a observação. É que a obtenção desse estágio do conhecimento ocorre ao longo de todos os dias e de todos os momentos de nossas vidas e de nossa existência, a todo o momento estamos adicionando alguma coisa ao nosso intelecto. Mesmo dormindo, ao relembrar de nossos sonhos, aprendemos algumas verdades $e$ adquirimos algum fundamento para um melhor entendimento da natureza humana, com as suas potencialidades e fragilidades. (WATTS, 1743, p. 35)

\section{Leitura}

Com esse método Watts explica que é possível compreender, de uma forma muito extensa, fatos, ações e pensamentos relativos à vida e a morte, da mais remota nação e as mais distantes eras e com tanta facilidade, "como se eles vivessem em nossa própria época e nação”. (WATTS, 1743, p.32)

Trazendo uma visão geral de seus métodos, Watts faz comparações entre os mesmos, na qual, afirma que pela leitura, pode-se aprender algo de qualquer aspecto da humanidade, enquanto que pela observação, aprende-se sobre aquilo que se está em contato direto e que pela conversação pode-se aproveitar apenas a assistência de algumas pessoas que estão próximas e que

\footnotetext{
${ }^{7}$ Outros métodos que ainda serão abordados
} 
vivem em uma mesma época, contemporâneos.

O autor chama a atenção para o perigo de se restringir apenas à reflexão a partir da leitura, sem observação ou conversação, o que ocasionaria em um conhecimento que será sempre muito limitado, nesse caso o aperfeiçoamento da mente surgiria somente através das meditações e compreensões próprias, se algo for interpretado de uma forma equivocada, o leitor permanece com o "erro", sem ter como obter outra posição relativa ao assunto. (WATTS, 1743, p. 35)

Mesmo apontando a importância da conversação, são feitas observações quanto a suas limitações, assim como em relação a outras fontes de conhecimento. $\mathrm{Na}$ conversação e em algumas palestras o que se obtém muitas vezes é somente o pensamento dos tutores ou amigos presentes, e embora eles possam ser brilhantes e muito úteis, podem a princípio, serem rápidos, desordenados e com dicas simples e sem plenitude, já na leitura há a possibilidade de revisar o que foi lido, o autor destaca que se pode consultar a mesma página várias vezes, e refletir sobre sucessivas passagens, nas horas serenas e de descanso, tendo o livro sempre à mão, enquanto que, o que se obtém pela conversação em aulas, muitas vezes é rapidamente perdido. (WATTS, 1743, p. 37)
Instruçôes Verbais para Palestras Públicas ou Privadas

O autor caracteriza esse método dizendo que "sempre há algo de mais alegre, mais agradável e divertido no discurso ao vivo de um sábio, erudito e bem qualificado professor, do que há na silenciosa e sedentária prática da leitura" (WATTS, 1743, p. 38). Segundo Watts a variação no tom de voz, a boa pronúncia, atraem a atenção, mantém a mente do ouvinte atenta, além de transmitir e introduzir as ideias das coisas de uma maneira mais viva e convincente, do que a simples leitura de livros no silêncio e no isolamento particular.

Um tópico que nos chamou muita atenção nesse método foi que Watts diz que o tutor ou instrutor, quando parafraseia $e$ explica outro autor, pode demarcar um ponto preciso de dificuldade ou controvérsia de seus alunos, e desdobrá-lo. Pode-se notar que o uso de artifícios que aproximam o assunto da vivência do seu aluno, já era amplamente difundido. Podemos citar, o uso de analogias, que se for bem empregado, pode facilitar o entendimento de um determinado assunto que estaria distante do cotidiano do aluno.

O professor teria o papel de facilitador do aprendizado, podendo assim mostrar, qual era a "doutrina dos ancestrais em um 
compêndio", o que poupa o trabalho da leitura de muitos livros. Nele, o professor pode informar quais as doutrinas ou sentimentos que estavam se desenvolvendo no mundo antes de se tornarem públicas; bem como familiarizar o aluno com os seus próprios pensamentos, experiências e observações que, talvez, nunca fossem publicadas para o mundo, e que ainda podem ser muito úteis e valiosas (WATTS, 1743, p. 38).

Segundo Watts, o instrutor nas palestras, pode fazer experimentos diante dos olhos dos espectadores, pode descrever figuras e diagramas, pontos nas linhas e ângulos e fazer demonstrações de uma maneira inteligente, utilizando os sentidos, que não podem ser tão bem feitos somente através da leitura, entretanto, o estudioso deixa claro que os aprendizes devem ter as mesmas figuras em um livro diante de si, isto é, que esses pormenores não sejam apenas mostrados, mas acompanhados pelos estudantes.

Acrescenta ainda que mesmo quando o assunto do discurso fosse "moral, lógica ou retórica e que não viesse diretamente sob a percepção dos sentidos, um tutor deveria explicar as suas ideias através de exemplos familiares, claros, comparativos, como raramente se encontra em um livro"(WATTS, 1743, p. 39-40)). Novamente ressaltamos o

\footnotetext{
${ }^{8}$ Espécie de resumo ou apostila.
}

quanto é interessante notar as ideias de John Locke influenciando a obra de Watts, pois em um trecho do An Essay Concerning $\mathrm{Hu}$ man Understanding, Locke demonstra a mesma preocupação, de ser necessário tornar algo compreensível para aqueles que não estavam habituados com um determinado assunto. Em suas palavras:

Quando uma pessoa faz uso de um nome de alguma ideia simples, e percebe que não é entendida, ou que pode produzir um engano, é necessário, pelas leis da engenhosidade e pelo objetivo do discurso, declarar o significado e tornar conhecido o que a ideia pretende significar. [...] Deste modo, para tornar conhecido a um camponês o que a cor feuillemorte significa, será suficiente dizer-lhe que é a cor de folhas secas caindo no outono. (LOCKE, 1836, p. 378)

Watts afirma que a presença do professor para sanar dúvidas e remover as dificuldades dos discípulos é fundamental. Quando o tutor em suas aulas entrega alguma questão difícil, ou se expressa de maneira que o ouvinte não capta claramente as suas ideias, é sugerido que o mesmo tenha a oportunidade de, no mínimo quando a aula terminar, ou em outro momento adequado, inquirir sobre como a sentença deve ser entendida ou como a dificuldade pode ser es- 
clarecida e removida. Ressalta ainda que seria ideal ter uma livre conversa com o tutor, ou no meio da aula ou mais no final dela, relativo às dúvidas ou dificuldades que ocorreram para o ouvinte, conduzindo a dúvida a uma conversa ou a um discurso participativo para todos. (WATTS, 1743, p. 39)

\section{Conversação}

$\mathrm{O}$ autor ainda afirma que, às vezes, em um diálogo, embora ambas as partes falem, ainda assim o predomínio de saberes está sobre um lado, ele exemplifica com um encontro entre um professor e um aprendiz que discursam juntos, que debatem determinado tema, mas não deixa claro qual dos dois é o detentor do saber. Nesse caso, finaliza Watts, o benefício é frequentemente mútuo, isto é, ambos aprenderão se o professor utilizar do método de conversação. (WATTS, 1743, p.32)

Quando aborda este método, o autor diz que quando se conversa com um amigo sábio, tem-se na sua presença, a ajuda para explicar toda palavra e sentimento que parecem obscuros em seu discurso e para esclarecer todo o significado, então assim, o risco de uma interpretação ou entendimento equivocado é menor, enquanto que em um livro, tudo o que para o leitor é realmente incompreensivel pode permanecer sem ser entendido, sem solução, uma vez que o au- tor não está ao seu lado para ser inquirido sobre o seu sentido. (WATTS, 1743, p. 40) Gostaríamos de ressaltar que Watts não atribui graus de importância diferentes entre os seus métodos, porém, traz uma visão crítica sobre cada um e expõe as suas limitações.

Ao fazer uma comparação entre a Conversação e a Leitura, Isaac Watts deixa explícito que as dificuldades que surgem na mente do aprendiz podem ser removidas por uma esclarecedora palavra da pessoa com a qual se dialoga o que seria uma desvantagem da Leitura, que se uma dificuldade ou questão surgir em seus pensamentos, dos quais o autor não tenha mencionado, devese contentar com a ausência de uma resposta ou solução para isso, afinal "Livros não podem falar". (WATTS, 1743, p. 41)

Segundo Watts, não somente as dúvidas que surgem sobre algum assunto do discurso são facilmente propostas e resolvidas na conversação, mas as verdadeiras dificuldades encontradas nos livros e nos estudos particulares podem ser resolvidas com uma conversa informal. Pode acontecer que durante uma leitura e reflexão sobre um assunto complicado, surja uma dúvida que permaneça vários meses sem solução, apenas porque se tenha trilhado um caminho de raciocínio errado e acabamos insistindo num erro que nem se sabe se é real. Watts reco- 
menda corrigi-lo logo no primeiro passo, anotando a dificuldade durante a leitura $e$ expondo a dúvida a algum conhecido, no intuito de saná-la. Assim, a dificuldade desaparecerá. (WATTS, 1743, p. 41)

A conversação é responsável por despertar conceitos úteis anteriormente estudados, de dentro da memória. De acordo com Watts, através do mútuo discurso, a "alma é despertada", visto que é nesse momento que os envolvidos no debate expõem e compartilham suas ideias, em suas palavras: "Um homem de ampla leitura, sem conversação é como um avarento, que vive somente para ele mesmo" (WATTS, 1743, p. 42). Ele afirma que é nas conversas é que ocorre o despertar da vontade de aprender, como no seguinte trecho:

Frequentemente tem acontecido em discursos livres, que novos pensamentos estranhamente saem $e$ as sementes da verdade brilham e resplandecem através da companhia de um interlocutor, a calma e silenciosa leitura nunca teria excitado tais sementes. Pela conversação, ambos irão dar $e$ receber o benefício; como pedras, quando colocadas em movimento e atritadas uma contra a outra, produzem um fogo vivo em ambos os lados, que nunca teria surgido dos mesmos materiais rígidos em um estado de repouso. (WATTS, 1743, p. 44)
Outra vantagem considerada por Watts, é que a conversação fornece ao estudante o conhecimento dos homens, como a leitura fornece através do livro. Para ele, um homem que vive todos os seus dias entre os livros pode acumular inúmeros conceitos, mas deve ser considerado um mero estudioso, um contemplador do mundo, para esse, falta o diálogo, o debate, que só é possível com a conversação. Sendo assim, ele traz uma discreta crítica à maneira como as faculdades moldam os seus alunos, padroniza e limita os conhecimentos dos mesmos, ao dizer que:

Um eremita, que tem sido calado em sua cela, em uma faculdade tem contraído um tipo de molde e uma ferrugem em cima de sua alma $e$ todos os seus ares de comportamento tem certo constrangimento para eles; mas esses ares incomodados são desgastados pelos graus da companhia; a ferrugem e o molde são arquivados e escovados pela conversação educada, o estudante tornase um cidadão ou um cavalheiro, vizinho, amigo, ele aprende como vestir seus sentimentos nas cores justas como bem os estabelece em uma luz mais forte. (WATTS, 1743, p. 44)

Watts aconselha ao professor que ao perceber uma pessoa inexperiente em matéria de debate, deve guiá-la a um conhecimento claro da matéria (WATTS, 1743), ou 
seja, quando o professor observar que o seu aluno não está tendo um "vocabulário científico" adequado para dialogar sobre determinado assunto, cabe a ele fazer o ajustamento deste, apresentando primeiro uma forma de expressão popular e então fazer a transição para a linguagem coloquial.

Ao finalizar esse método, o autor afirma que quando o indivíduo faz algum uso de seus conhecimentos adquiridos no mundo, ele está aperfeiçoando a teoria pela prática, entretanto, para ele não basta aplicar o conhecimento, deve-se considerar que algo mais é necessário, além de conhecimentos dos homens em livros, e, portanto, desenvolveu o próximo método.

\section{Meditação ou Estudo}

Através desse método é que se constroem várias conclusões e se estabelecem princípios gerais do conhecimento, comparando as várias ideias que derivam dos sentidos, ou das operações mentais e assim, unilos para formar opiniões e novas proposições. Além de ser responsável pela fixação da aprendizagem, e gerar uma forma própria de julgamento da verdade ou falsidade, o poder ou a fragilidade do que os outros falam ou escrevem. (WATTS, 1743, p. 33)

Pode-se perceber que esse método é de extrema importância para o efetivo do aperfeiçoamento da mente que Watts objetiva alcançar, apenas as aulas, as leituras e a conversação, sem uma reflexão, não são suficientes para fazer do homem um ser de conhecimento e sabedoria. Entretanto, sem os outros procedimentos?) uma pessoa não poderia formar um alicerce, uma fundamentação, para sua reflexão, para balizar seu conhecimento. É o próprio pensamento, a reflexão, o estudo e a meditação que devem atender a todos os outros métodos de aperfeiçoamento e melhorá-los. Mais uma vez é possível verificar uma semelhança com os escritos de Locke, ao tratar sobre a Percepção, ele traz a importância da observação acompanhada da reflexão própria do indivíduo, como segue o trecho abaixo:

Cada um saberá melhor o que é a percepção refletindo acerca do que ele mesmo faz, quando vê, ouve, sente etc., ou pensa, do que mediante qualquer explicação de minha parte. Quem quer que reflita acerca do que se passa em sua mente, não pode omiti-la e se não reflete, todas as palavras no mundo não podem levá-lo a ter qualquer noção dela. (LOCKE, 1836, p.81)

Neste ponto, Watts ressalta a necessidade da meditação e da organização das ideias, dizendo que todos os procedimentos abordados até este momento podem fornecer muitas ideias de outras pessoas, mas 
apenas através da meditação $e$ da organização dos pensamentos, é que se deve tirar conclusões, filtrar as ideias e concepções. A mente é responsável por julgar o que concorda ou discorda das ideias adquiridas $e$ formar proposições verdadeiras. Leitura $e$ conversação devem auxiliar nesse processo mental fornecendo conteúdos e argumentos para sustentar as proposições formadas, mas é o estudo e o raciocínio do indivíduo que devem determinar se essas proposições são verdadeiras e se esses argumentos são justos e sólidos. (WATTS, 1743, p. 45)

Segundo Watts, existem fatos e fenômenos que não seriam possíveis de se reproduzir, devido à distância, ao tempo e aos lugares onde tais coisas acontecem. Esses fatos são conhecidos através de consultas às outras pessoas e aos livros. Mas, depois de tudo, é por reflexão e julgamento próprios que se deve determinar o que aceitar e pelo trabalho da mente pode-se penetrar em temas do conhecimento e transportar o pensamento para muito longe, sobre muitos assuntos. É pelo raciocínio que se desenha qualquer verdade para o outro $e$ forma todo um esquema ou conhecimento a partir de umas poucas informações que são recebidas de alguém. Examinando essas situações, Watts conclui que:
Quem gasta todo o seu tempo ouvindo aulas, ou debruçado sobre os livros, sem observação, meditação ou conversa, terá mais um mero conhecimento histórico de leitura e de dizer apenas sobre o que os livros ou homens os informam $e$ até onde eles são dignos de nossos créditos e assentimentos. (WATTS, 1743, p. 47).

Finalizando em sua descrição do procedimento, Estudo ou Meditação, Watts diz que, através do mesmo, aperfeiçoam-se as informações que se têm adquirido pela observação, conversação e pela leitura: aquele indivíduo, que só conversa sem observação, leitura ou estudo obtém mais um leve e superficial conhecimento, e corre o risco de ser portador de equívocos; aquele que apenas confia em si mesmo, em seu isolamento $e$ em sua própria observação restrita das coisas e é ensinado apenas pelos próprios pensamentos, sem instrução por aula, leitura, ou conversação livre, está em perigo de se restringir a um vão conceito de si mesmo $e$ a um desprezo irracional pelos outros. Por fim, ele obtém apenas uma verdadeira, limitada e imperfeita visão e conhecimento das coisas que raramente lhe permite aprender a fazer alguma coisa útil do seu conhecimento.

\section{Considerações finais}

Isaac Watts conclui sua obra alertando que os cinco métodos de aperfeiçoamen- 
to apresentados devem ser desenvolvidos em conjunto, integrados, pois apenas dessa forma seriam aproveitados plenamente. Lembra-nos também, que para uma palestra, um orador ou um mestre, que vise uma melhor maneira para o aperfeiçoamento da mente de seus ouvintes deveria utilizar do maior número de métodos por ele descritos, mas alerta também que esses métodos deveriam ser utilizados de acordo com a necessidade do público e daquilo que se quer transmitir.

Na leitura dessa obra foi possível perceber que, além das observações e sugestões sobre os seus métodos, o autor apresenta uma visão crítica sobre a aquisição de conhecimentos que deveriam contribuir para que o indivíduo estivesse apto para o julgamento de questões da vida, estejam elas relacionadas com sua família, vizinhos ou com o governo, não sendo necessário (e até impossível) aprender tudo ou saber sobre tudo, mas, deveria sempre melhorar sua própria compreensão sobre o assunto que desejasse.

Apesar das contribuições da obra de Watts que apresentamos neste trabalho, pode-se perceber que o seu nome não é muito citado em compilações sobre pensadores $e$ filósofos do século XVIII, mas sim pelo seu envolvimento com a igreja protestante, conferindo-lhe destaque para a sua elaboração de hinos religiosos em inglês.

\section{Referências}

BALDINATO, José Otávio; PORTO, Paulo Alves. A química segundo Michael Faraday: Um caso de divulgação cientifica. 2009. 139 f. Dissertação - Interunidades em Ensino de Ciências: Modalidade Química, Universidade de São Paulo, São Paulo, 2009.

BELTRAN, Maria Helena Roxo; BELTRAN, Nelson Orlando. História da Química e Ensino: Experimentos e Atividades em Sala de Aula. In: BELTRAN, Maria Helena Roxo; SAITO, Fumikazu; SANTOS, Rosana Nunes e WUO, Wagner (Org). História da Ciência e Ensino: Propostas, Tendências e Construção de Interfaces. São Paulo. Ed. Livraria da Física, 2009, p. 173-182

BRASIL. Ministério da Educação e do Desporto. Parâmetros Curriculares Nacionais. Brasília: MEC, 1998.

BRASIL. Ministério da Educação e do Desporto. Diretrizes Curriculares para os cursos de ensino superior. Brasília: MEC, 2000.

DEL PINO, José Claudio; FRISON, Marli Dallagnol. Química: Um conhecimento científico para a formação do cidadão. Revista de Educação, Ciências e Matemática, v.1, n.1, p. 36-48, Ago/Dez. 2011. 
GIBBONS, Thomas. Memoirs of the Rev. Isaac Watts. London, 1780

GIL PÉREZ, Daniel. Contribución de la Historia y de la Filosofia de las Ciencias al desarrollo de un modelo de enseñanza/aprendizaje como investigación. Revista Enseñanza de las Ciencias, Barcelona, v.11, nº 2, p. 197 - 212, 1993.

HODSON, Derek. Experiments in Science and Science Teaching. Educational Philosophy and Theory, New Zealand, v. 20(2), 53-66, 1988

LOCKE, John. An Essay Concerning Human Understanding. London, 1836.

LOPES, Alice Ribeiro Casimiro. Bachelard: O filósofo da desilusão. Cad. Cat. Ens. Fís., Santa Catarina, v.13, nº 03, p. 248-273, Dez. 1996

MARTINS, Carlos Estevam; MONTEIRO, João Paulo. John Locke (1632-1704). Coleção Os Pensadores, São Paulo: Editora Abril Cultural, $2^{\text {a }}$ edição, 1978

WATTS, I. The Improvement of the Mind: or, a Supplement to the Art of Logic: Containing a Variety of Remarks and Rules for the Attainment and Communication of Useful Knowledge, in Religion, in the Sciences, and in Common Life, Londres, 1743.

Recebido em: 15/03/2017

Aprovado em: 05/06/2017 